\title{
Estimation and spatial mapping of seismicity parameters in western Himalaya, central Himalaya and Indo-Gangetic plain
}

\author{
Monalisha NAYAK* (D) and T G Sitharam \\ Department of Civil Engineering, Indian Institute of Science, Bengaluru 560 012, India. \\ *Corresponding author.e-mail: monalishan@iisc.ac.in
}

MS received 31 August 2017; revised 18 June 2018; accepted 19 June 2018; published online 23 February 2019

The present study attempts to assess the seismic hazard parameters $\left(a, b\right.$ and $\left.M_{\mathrm{c}}\right)$ and their spatial variation in western Himalaya, central Himalaya and Indo-Gangetic plain areas $\left(19-38^{\circ} \mathrm{N}\right.$ and $72-$ $91^{\circ} \mathrm{E}$ ). The earthquake catalogue is prepared from different available sources, within a region of $500 \mathrm{~km}$ surrounding the study area, in moment magnitude scale. The maximum likelihood estimation method is used for spatial variation of seismicity parameters. The study area is disaggregated into small grids of $0.5^{\circ} \times 0.5^{\circ}$, and the spatial variation of seismicity parameters is analysed for the complete catalogue period. A significant variation in seismicity parameters is observed while moving from west to east along the Himalayan belt within the study area. Due to significant variations in seismicity parameters, instead of assigning a lumped value of seismic hazard parameter to the entire region, distributed seismic hazard parameter is assigned by dividing the entire area into five zones, of similar level of seismicity. The estimated seismicity parameter $a$ for these zones varies from 4.28 to 6.18 , and for $b$, it varies from 0.80 to 1.03 . Using these Gutenberg-Richter parameters $a$ and $b$, the present study estimated the return periods and probability of different magnitudes of earthquake for each zone.

Keywords. Himalayan region; Indo-Gangetic plain; seismicity parameters; maximum likelihood estimation; return period.

\section{Introduction}

One of the primary objectives of probabilistic seismic hazard analysis of any region is to assess the seismic hazard parameters or seismicity parameters of that region. Himalayan region, located in the plate boundary area of Indian plate and Eurasian plate, is one of the most seismically active region in the world. Several studies have been conducted in the past to estimate seismic parameters in and around the Himalayan region. These studies have assessed seismic parameters in terms of Gutenberg-Richter $(\mathrm{G}-\mathrm{R})$ parameters $a$ (or $\alpha$ ) and $b$ (or $\beta$ ), magnitude of completeness $\left(M_{\mathrm{c}}\right)$, expected maximum magnitude $\left(M_{\max }\right)$, mean activity rate, etc., based on instrumental or both historical and instrumental earthquake catalogue by using different methodologies. Some of these significant studies have been conducted by Shanker and Sharma (1998), Raghukanth (2010), Kolathayar et al. (2012), Yadav et al. (2012, 2013), Rout et al. (2013), Chingtham et al. (2014, 2016), Ali and Shanker (2017) and Bungun et al. (2017). Most of these studies estimated the seismic parameters in certain parts of Himalayas or entire India except for the study by Shanker and Sharma 
(1998). Shanker and Sharma (1998) estimated the seismic parameters of Himalayas and IndoGangetic plain $\left(20-36^{\circ} \mathrm{N} ; 69-100^{\circ} \mathrm{E}\right)$ by dividing this region into six different seismic zones. None of the recent studies have estimated seismic hazard parameters of this combined region of Himalayas and Indo-Gangetic plain. The present study attempts to estimate the seismic hazard parameters of Himalayas and Indo-Gangetic plain, using an updated earthquake catalogue excluding northeast Himalaya.

The present study area, northwest Himalaya, central Himalaya and Indo-Gangetic plain is bounded between latitude of $19-38^{\circ} \mathrm{N}$ and longitude of $72-91^{\circ} \mathrm{E}$ (figure 1). This study estimates the seismicity parameters $a, b$ and $M_{\mathrm{c}}$ and their spatial distribution in and around the study region using a combined earthquake catalogue of historical (pre-instrumental) and instrumental earthquake data. In the case of seismicity studies, it is necessary to use comprehensive and complete catalogue, which uses maximum number of events to obtain high-quality and reliable results. To achieve this, an earthquake catalogue was prepared in homogeneous moment magnitude scale by compiling available data from different sources for a period of earliest availability till December 2016. Using this updated earthquake event catalogue, the analysis was carried out to estimate the seismicity parameters $\left(a, b\right.$ and $\left.M_{\mathrm{c}}\right)$ of the study region based on maximum likelihood estimation method and also their spatial distribution. Based on spatial distribution of seismic parameters, the entire study area was divided into five zones and the corresponding seismicity parameters were estimated for each zone. The return period of earthquakes of different magnitudes, for all five zones, were estimated based on seismicity parameters $a$ and $b$. Also, the probability of future earthquakes for these five zones was assessed based on the estimated seismicity parameters.

\section{Seismotectonic settings of study area}

Based on seismotectonic, the Indian subcontinent is divided into three regions viz., most active Himalayan region, moderately active Indo-Gangetic plains and the least active peninsular shield region (Kayal 2008). The tectonics of the present study area is primarily influenced by tectonics of Himalayas and of inter-plate type. The complex tectonics of the Himalayan region is due to continuous convergence and subduction of Indian plate under the Eurasian plate. The convergence

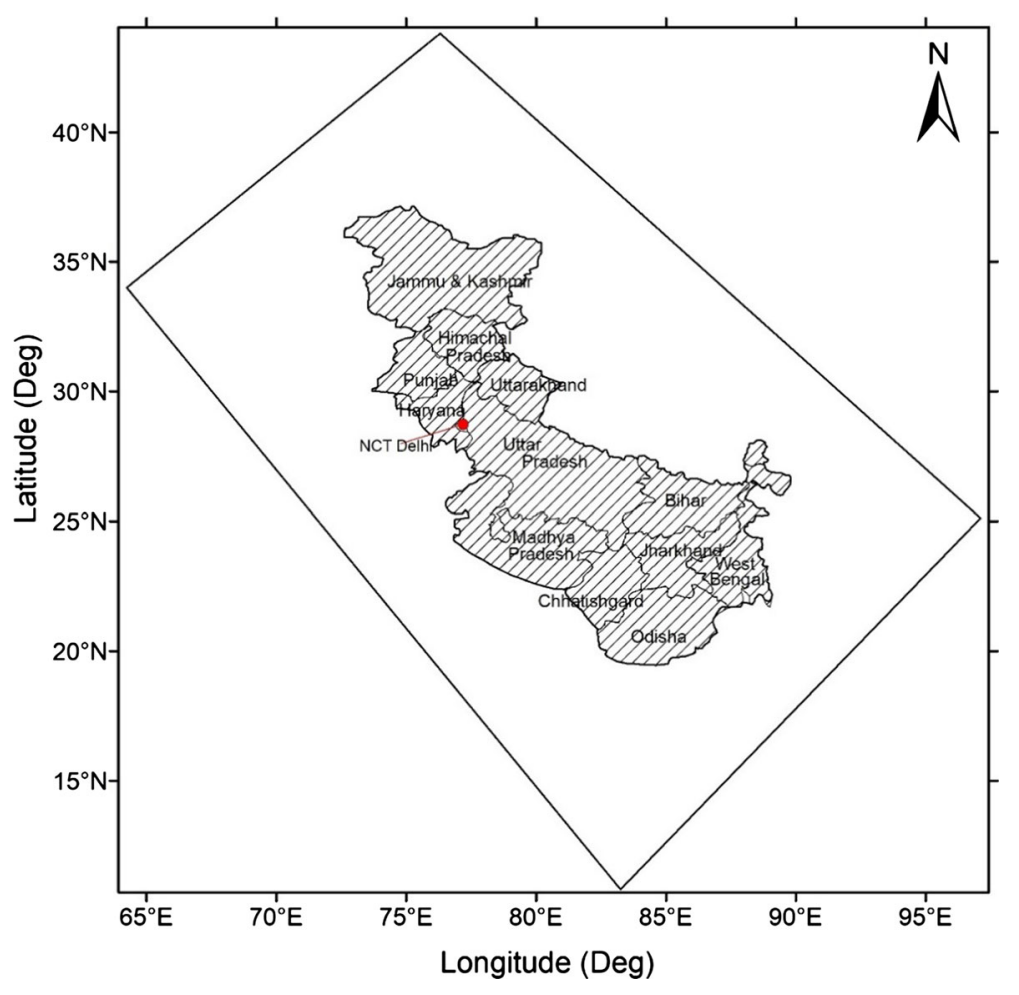

Figure 1. Location of the study area. 
rate along the Himalayan region varies from 11 to $22 \mathrm{~mm} / \mathrm{yr}$ (Stevens and Avouac 2016; Bungum et al. 2017), and this convergence makes the Himalayan region most active deforming region in the world (Singh and Shanker 2015; Ali and Shanker 2017). The seismic activity of the study region is mainly shallow in nature, and the focal mechanism is mainly thrust faulting type. With increase in focal depth, the thrust faulting decreases and the strike slip faulting occurs in a greater depth. The important and primary tectonic features in the Himalayan region are the main boundary thrust, the main central thrust and the Himalayan frontal thrust. Many significant earthquakes originated along these active thrusts of the Himalayas. Based on seismicity of Himalayas, a large portion along the Himalayas was identified as central seismic gap (Bilham et al. 2001; Rajendran and Rajendran 2005). This seismic gap area did not experience any earthquake for a long time till 25 April 2015 Nepal earthquake. Year 2015 Nepal earthquake unzipped the locked Himalayan thrust, and was considered to be the maximum probable zone for any future earthquakes facilitating further rupture in these areas (Avouac et al. 2015).

Besides these mega thrust faults, a lot of active and hidden tectonic features like faults, lineaments, sutures and ridges are also present in the Himalayan region as well as in the Indo-Gangetic plains. Some of the important ones present in the study region are Karakoram fault, Jwalamukhi thrust, Ramgharh thrust, North and South Almora thrust, Great Boundary fault, Alkananda fault, Mahendragarh Dehradun fault, Moradabad fault, Manali fault, Lucknow fault, Patna fault, Altyn Tagh fault, Shyok suture, Indus Suture zone, Indus Tsango Suture zone, etc. These tectonic features are well documented and published in the Seismotectonic Atlas of India (SEISAT 2000) by Geological Survey of India. These features were collected from SEISAT for the present study region of western and central Himalayas and Indo-Gangetic plains to prepare the seismotectonic map of the study region (figures 2 and 3$)$.

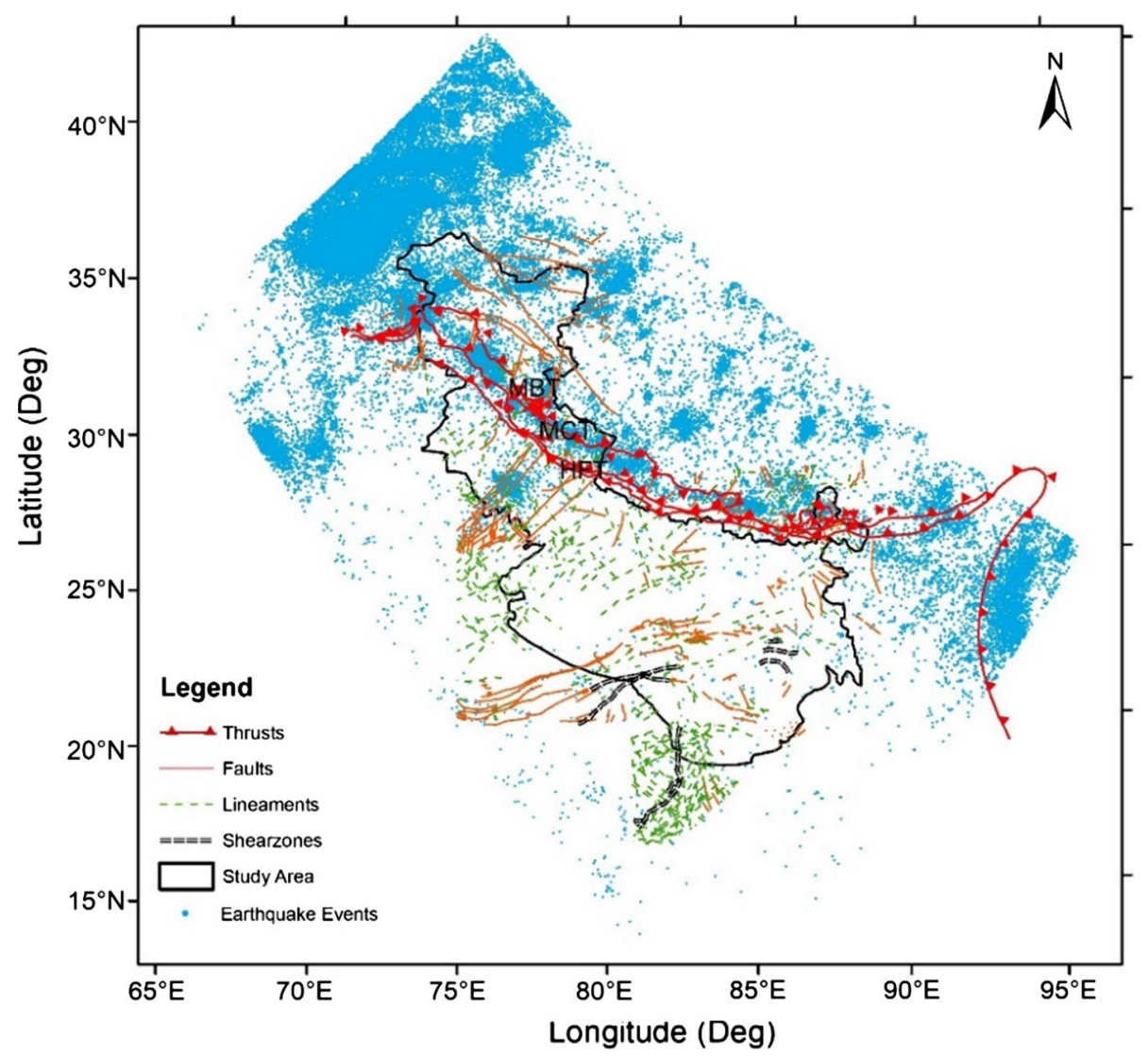

Figure 2. Spatial distribution of past earthquakes (including foreshock and aftershocks) in the study area and its vicinity with tectonic features. 


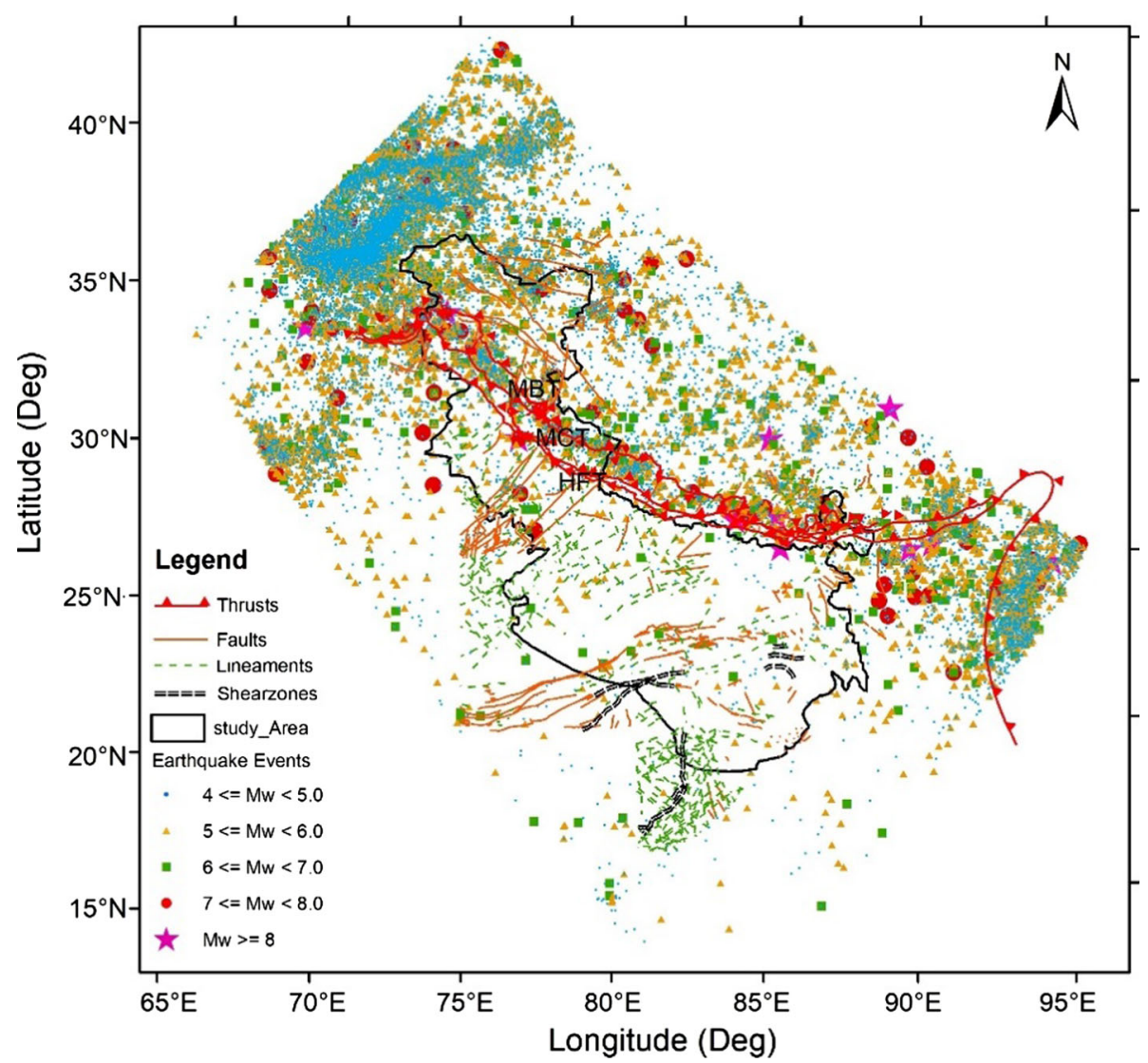

Figure 3. Seismotectonic map of study area for the de-clustered catalogue.

\section{Data compilation and preparation of catalogue}

A comprehensive and complete earthquake catalogue is necessary for assessment of seismic parameters of any region because short and incomplete records can lead to biased estimation of recurrence model parameters (Stepp 1972). In the present study, the earthquake catalogue was prepared considering both historical and postinstrumental period earthquakes for a region of $500 \mathrm{~km}$ zone surrounding the selected study area. The instrumental data were collected from different international and national agencies such as US Geological Survey (USGS), International Seismological Centre (ISC) bulletin, Incorporated Research Institutions for Seismology (IRIS), Advance National Seismic System (ANSS) and India Meteorological Department (IMD), having either global or regional seismic networks. The historical earthquake events were primarily collected from the available literature. Compiling all these information from the above stated sources, and the catalogue prepared by the National Disaster Management Authority of India (NDMA 2011), the raw/clustered earthquake event catalogue for the present study was prepared. As the earthquake events were collected from different sources, there is good possibility of repetition of events in the catalogue. The repeated events were removed from the catalogue based on their location (latitude and longitude), date and time of occurrence and magnitude and depth. However, while securitising the events priority was given to the data collected from USGS, compared to other sources. These earthquake events in the raw catalogue were combined with the tectonic features of the study region to form the seismotectonic map of the study area as shown in figure 2 .

Moment magnitude, $M_{\mathrm{w}}$, represents the actual size of the earthquake which is directly related to the seismic moment $\mathrm{M}_{\mathrm{o}}$. Hence, all other types of earthquake magnitudes are converted to moment magnitude scale to have a homogeneous earthquake catalogue. In this study, the conversion of $M_{\mathrm{b}}$ to $M_{\mathrm{w}}$ was done using general orthogonal regression analysis correlation given by Das et al. (2013), which is specific to the Indian Himalayan region. The correlation based on general orthogonal regression analysis given by Wason et al. (2012) was used 
Table 1. Statistics of earthquake events in the de-clustered catalogue.

\begin{tabular}{lr}
\hline $\begin{array}{l}\text { Magnitude range } \\
\left(M_{\mathrm{w}}\right)\end{array}$ & $\begin{array}{r}\text { No. of } \\
\text { events }\end{array}$ \\
\hline $4-4.9$ & 12,852 \\
$5-5.9$ & 5086 \\
$6-6.9$ & 603 \\
$7-7.9$ & 104 \\
$>=8$ & 19 \\
Total & 18,664 \\
\hline
\end{tabular}

to convert $M_{\mathrm{s}}$ to $M_{\mathrm{w}}$. For converting $M_{\mathrm{L}}$ to $M_{\mathrm{w}}$ least-square regression analysis correlation given by Kolathayar and Sitharam (2012) was used, as no other such relations are found for the Indian Himalayan region. For converting MMI to $M_{\mathrm{w}}$, the method used by Raghukanth (2010) was used. Using the above-mentioned correlations, a homogeneous earthquake catalogue was prepared for the present study area.

The homogeneous catalogue prepared in the above steps contains the main shocks as well as the foreshocks and aftershocks. In the present study, de-clustering (i.e., removal of dependent events such as foreshocks, aftershocks and clusters from main events) was done based on the algorithm given by Uhrhammer (1986) using the ZMAP software (Wiemer 2001). The number of earthquake events in the de-clustered catalogue for different magnitude ranges, from the earliest available to 2016 , is given in table 1 . The prepared seismotectonic map of the study area for the de-clustered catalogue is shown in figure 3. The completeness period of each magnitude range was evaluated, and the seismicity parameters were estimated in the following steps for the entire period of the catalogue.

\section{Estimation of seismicity parameters}

The level of seismicity of a region is assessed from the seismic parameters $a, b$ and $M_{\mathrm{c}}$. In the present study, $a$ and $b$ were estimated using G-R recurrence law (Gutenberg and Richter 1944). The $\mathrm{G}-\mathrm{R}$ law is given by

$$
\log \left(\lambda_{m}\right)=a-b M_{\mathrm{w}}
$$

where $\lambda_{m}$ is cumulative number of earthquakes with magnitude $\geq m, a$ and $b$ are the seismicity parameters and $M_{\mathrm{w}}$ is the moment magnitude. $a$ signifies the background seismicity, i.e., it gives the general level of earthquake activity in a region and is the slope of the frequency-magnitude distribution (FMD), which gives the distribution of magnitude size in a region. The magnitude of completeness, $M_{\mathrm{c}}$, is defined as the minimum magnitude at which $100 \%$ of events in a spacetime window is detected (Rydelek and Sacks 1989; Woessner and Wiemer 2005). Below this magnitude, a fraction of events is missed by the seismic network because they may be either too small to be recorded by seismic stations or they are below the magnitude of interest or they are mixed with larger events and therefore were undetected.

The spatial variation of all seismicity parameters, as stated above, were investigated using the seismic tool ZMAP (Wiemer 2001). For this, the selected study area was divided into grids of size $0.5^{\circ} \times 0.5^{\circ}$ and the seismicity parameters were evaluated at the centre of each grid. All evaluations were based on magnitude of completeness, $M_{\mathrm{c}}$, of prepared earthquake catalogue and the period of completeness of the de-clustered catalogue. $M_{\mathrm{c}}$ was evaluated by one of the most widely known methods suggested by Wiemer and Wyss (2000), which is based on power law fitted to the FMD relationship. The value of $M_{\mathrm{c}}$ was calculated at the centre of all grid points considering all the events within a radius of $500 \mathrm{~km}$ around the centre of the grids. The parameter $b$ was estimated from maximum likelihood method (Aki 1965; Bender 1983; Utsu 1999) as shown in the equation

$$
b=\frac{\log _{10} e}{m_{\text {mean }}-\left(M_{\mathrm{c}}-(\Delta m / 2)\right)},
$$

where $m_{\text {mean }}$ is the mean magnitude of sample, $M_{\mathrm{c}}$ is the magnitude of completeness and $\Delta m$ is the magnitude bin size. In order to get better estimation of events whose magnitudes are greater than or equal to $M_{\mathrm{c}}$ were considered, and also number of such events per grid should be at least 50 (Utsu 1965, 1999). A bootstrap method was used to estimate the uncertainties associated with estimation of Chernick (1999) and Schorlemmer et al. (2003).

\section{Results and discussions}

In the present study, estimation of $M_{\mathrm{c}}$ was carried out using the method suggested by Wiemer and Wyss (2000). Figure 4 shows the spatial distribution of $M_{\mathrm{c}}$, and figure 5 shows the uncertainties involved with $M_{\mathrm{c}}$. The magnitude of completeness, $M_{\mathrm{c}}$, varies from 4.4 to 4.85 in the seismic 


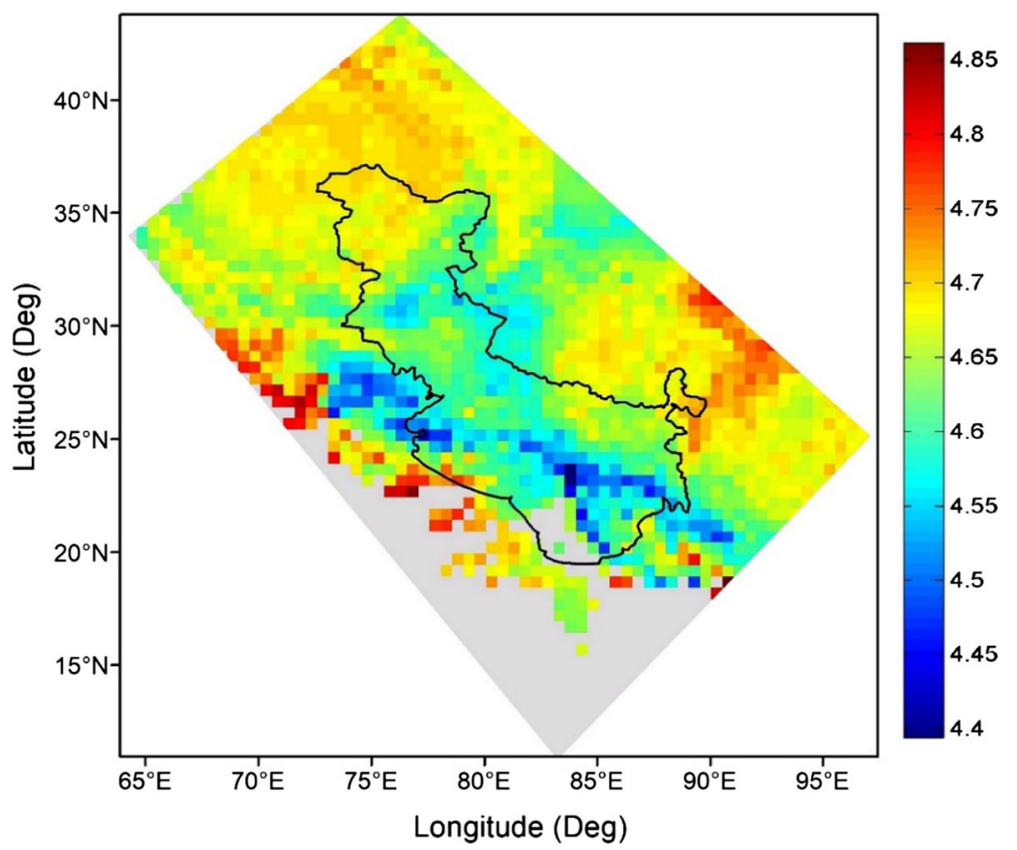

Figure 4. Spatial variation of magnitude of completeness $M_{\mathrm{c}}$ from the de-clustered catalogue.

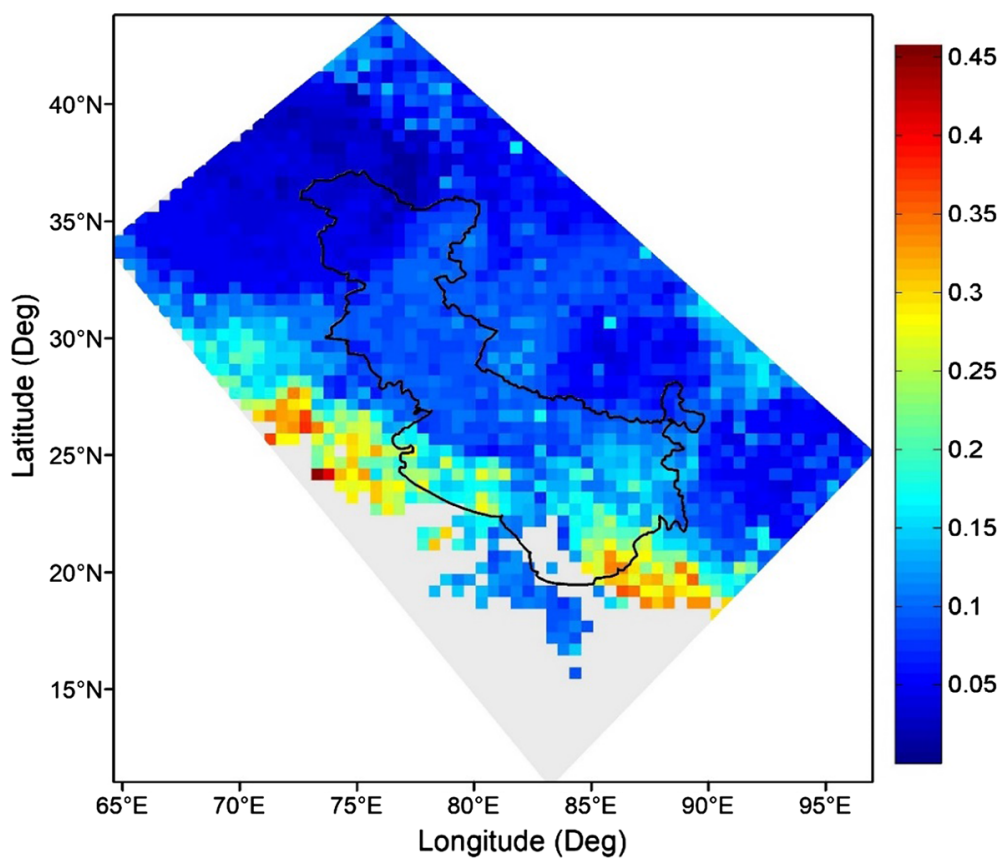

Figure 5. Spatial variation of standard deviation of magnitude of completeness $M_{\mathrm{c}}$ from the de-clustered catalogue.

study area. Most part of Kashmir in the western Himalayan region and Sikkim in central Himalaya show $M_{\mathrm{c}}$ as 4.7. In majority of the study area, $M_{\mathrm{c}}$ ranges from 4.5 to 4.6 , which includes part of the Himalayan region and Indo-Gangetic plain. In most part of the study area, the uncertainties in estimation of $M_{\mathrm{c}}$ vary from 0.05 to 0.15 except a few grid points where the uncertainties are high, which vary from 0.25 to 0.3 . The regions having high uncertainties may be due to lack of recording of smaller earthquake events in those areas. Chingtham et al. (2014) estimated the spatial distribution of $M_{\mathrm{c}}$ for northwest Himalaya and adjoining region considering $M_{\mathrm{w}} \geq 2.5$. It showed that Himalayan areas show higher $M_{\mathrm{c}}$ as compared to Indo-Gangetic plains. Yadav et al. (2012) have estimated the same for northwest Himalaya and adjoining region considering $M_{\mathrm{w}} \geq 4.0$ and showed 


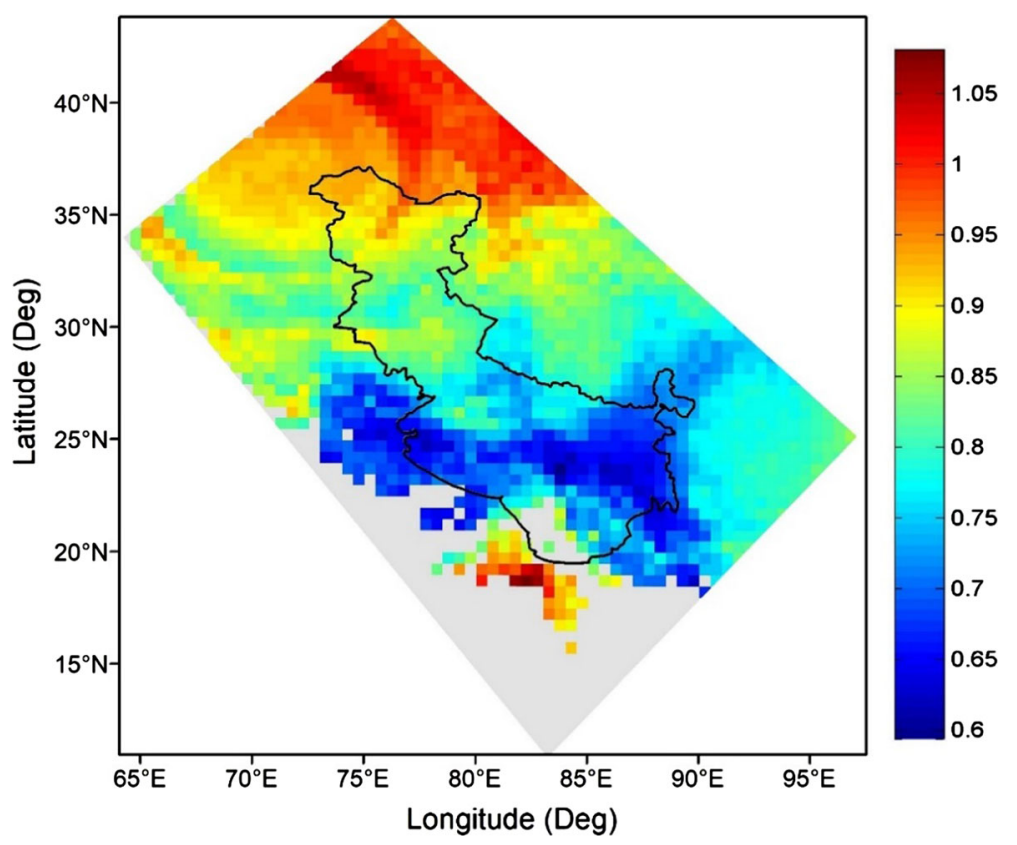

Figure 6. Spatial variation of parameter $b$ from the de-clustered catalogue in and around study area.

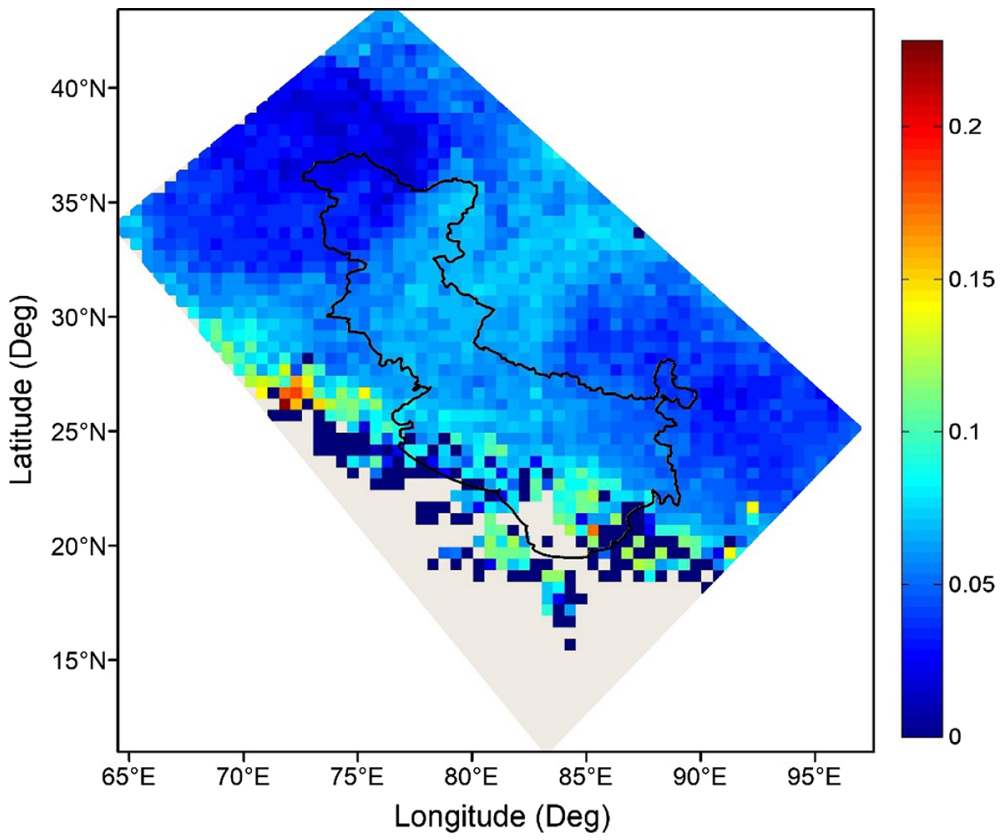

Figure 7. Spatial variation of standard deviation of $b$ value from the de-clustered catalogue in and around study area.

that $M_{\mathrm{c}}$ varies between 4.3 and 4.7 , which matches the present study. Kolathayar et al. (2012) have studied the spatial distribution of magnitude of completeness for entire India considering $M_{\mathrm{w}} \geq 4.0$ and have shown that $M_{\mathrm{c}}$ for the Himalayan area varies from 4.5 to 5.0 .

Spatial variation of parameter $b$ and its standard deviation using the de-clustered catalogue is shown in figures 6 and 7, respectively. For the seismic study area, $b$ varies from 0.6 to 1.05 and for the study area it varies from 0.6 to 0.95 .

From figure 6 , it is observed that $b$ decreases from west to east along the Himalayan range. The standard deviation of $b$ is less than 0.05 for most part of the study area, conforming to lesser uncertainties in the evaluation of $b$. Shanker and Sharma (1998) divided the Himalayan region and Indo-Gangetic plain into six zones and estimated the seismicity 


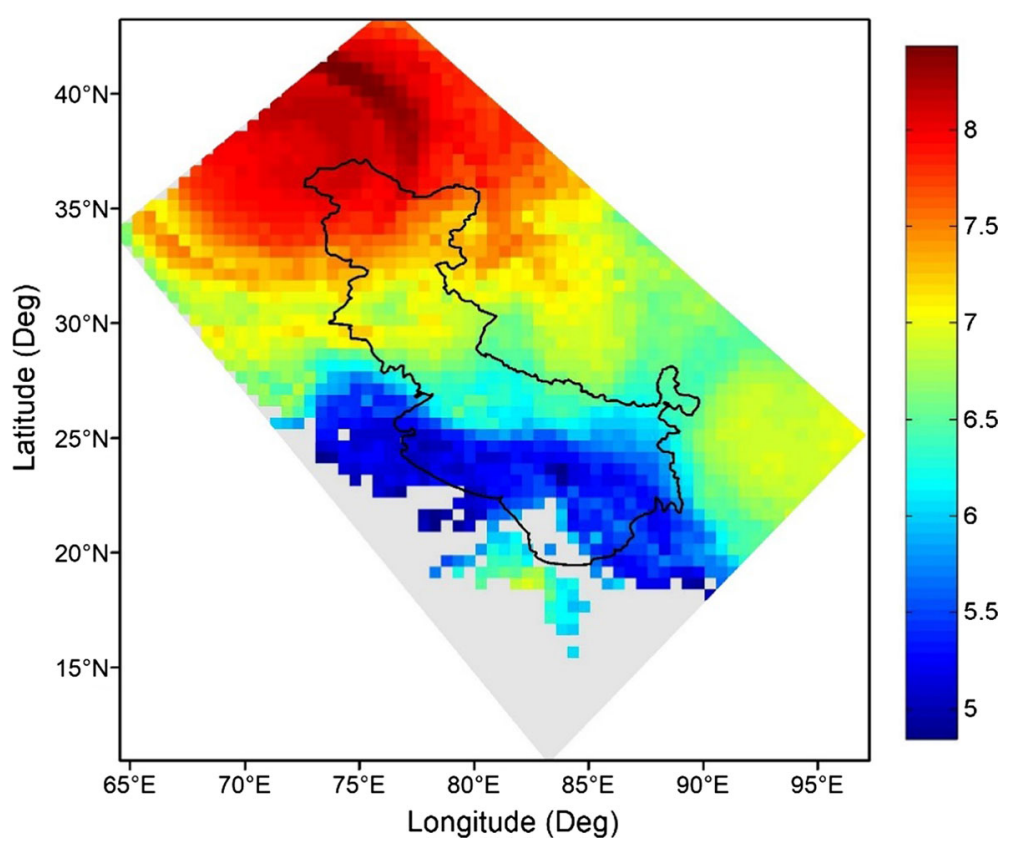

Figure 8. Spatial variation of parameter $a$ from the de-clustered catalogue in and around study area.

parameters for each zone. They obtained the highest $b$ of 1.38 pertaining to Hindukush Pamir region. Except this, for other five zones, $b$ varies from 0.63 to 0.94 and decreases from west to east along the Himalayan range which matches the present study. Raghukanth (2010) studied the spatial variation of seismic parameters for entire India and found that for Himalayan region and Indo Gangetic plain region, $b$ varies from 0.7 to 0.95, which matches the present study. Yadav et al. (2012) have shown that $b$ varies from 0.86 to 1.25 for northwest Himalaya and adjoining area.

Chingtham et al. (2014) have shown that value of $b$ and standard deviation of $b$ varies from 0.68 to 1.51 and 0.026 to 0.153 , respectively, for northwest Himalaya and adjoining area. Chingtham et al. (2016) divided the northwest Himalaya and adjoining area into five zones based on past seismic history, tectonics and focal mechanism and evaluated the seismicity parameters for each zone. They have shown that $b$ varies from 0.92 to 1.22 for northwest Himalaya and adjoining area. The present study has a good match with the past findings of different studies, and the differences in the estimation of $b$ may be due to earthquake event catalogue time period, their sources and method of analysis.

The spatial distribution of seismic parameter $a$ is shown in figure 8. From this it can be inferred that $a$ varies from 5 to 8 in the study area. As $a$ represents the level of seismicity of any region, the observed higher value of $a$ varies from 7.0 to 8.0 in the western Himalayan area, lower value of $a$ ranging $6.0-7.0$ in the central Himalayan region and the least value of $a$ ranging 5.0-6.0 in the IndoGangetic plain area, which matches the studies that the Himalayan region is the most seismically active and Indo-Gangetic plain is moderately seismically active in the Indian subcontinent.

In can also be observed that like parameter $b$, parameter $a$ also decreases moving from west to east along the Himalaya. Chingtham et al. (2016) have reported that $a$ varies from 6.58 to 8.60 in northwest Himalaya which matches the present study. Kolathayar et al. (2012) have shown that a varies from 4.0 to 7.6 in the Himalayan region and decreases from west to east along the Himalaya, which also matches the findings of the present study.

The seismic parameters, $a, b$ and $M_{\mathrm{c}}$ were not evaluated for some of the regions (shown as empty values in figures $4-8$, as those grids do not have adequate number of earthquake events (minimum 50) with magnitude equal to or greater than $M_{\mathrm{c}}$.

Figure 9 presents the FMD of the entire study area pertaining to the earthquake catalogue for the time period earliest available to 2016. From the FMD, seismic parameters, $a, b$ and $M_{\mathrm{c}}$ were estimated at 8.13, $0.87( \pm 0.03)$ and $4.7( \pm 0.05)$, respectively. Bungum et al. (2017) have shown the value of $a$ as 5.37 to 6.14 and that of $b$ as 0.95 to 1.00 for northwest and central Himalaya. 


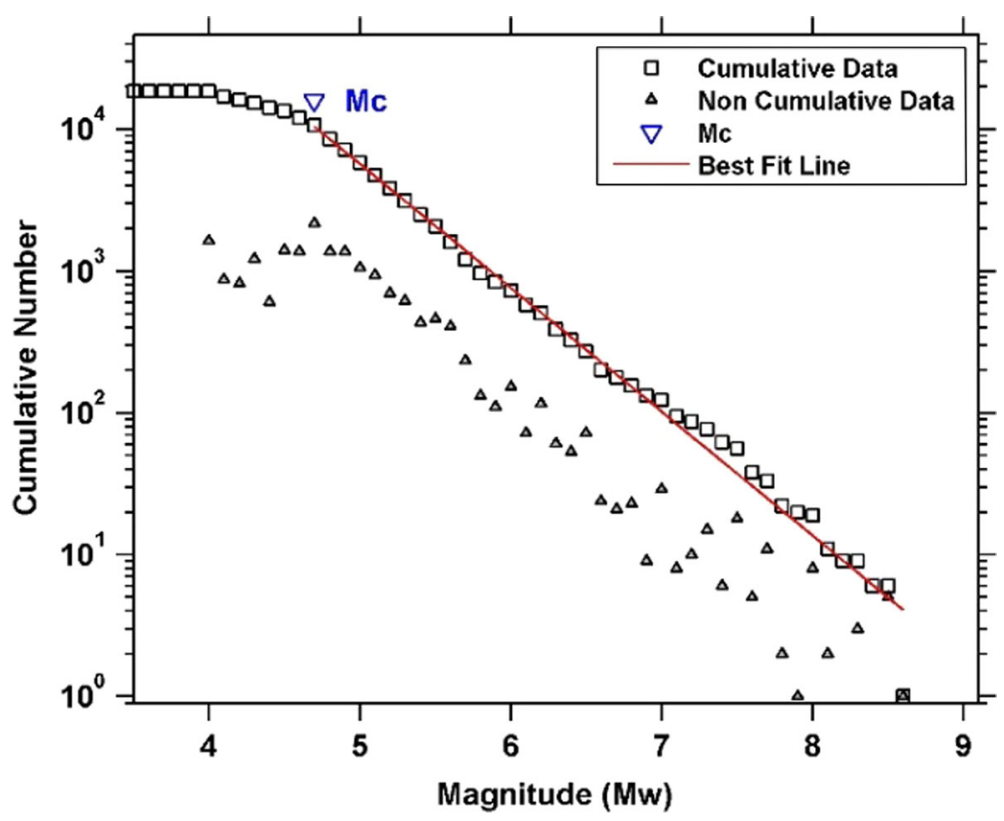

Figure 9. FMD relationship for the entire study area.

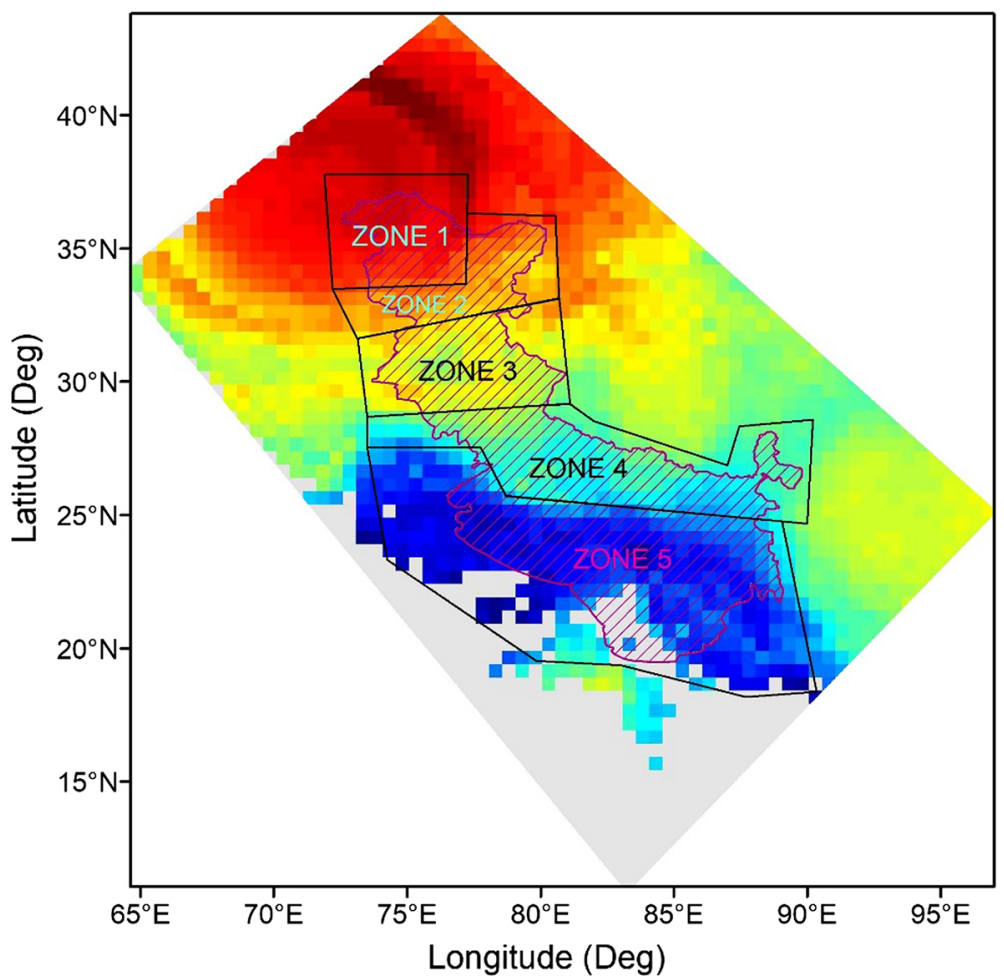

Figure 10. Identified seismic source zones based on seismicity parameters (variation of $a$ value is shown in background).

It has already been discussed, that these seismic parameters vary significantly throughout the study area, hence assigning a unique value to them may not hold good for seismic hazard analysis. To overcome this problem, the study area was divided into five seismic zones as shown in figure 10 based on magnitude of $a$, which gives the level of seismicity of any region. This division is not for the seismic zoning; rather it is assumed that a similar level of seismicity is observed within each zone. This will be helpful for seismic hazard analysis of the study area. For each zone, the FMD was plotted and corresponding seismic parameters were estimated, which is given in table 2 . The mean annual 
Table 2. Estimated seismicity parameters of all five seismic zones.

\begin{tabular}{lcccccc}
\hline $\begin{array}{l}\text { Sl. } \\
\text { no. }\end{array}$ & $\begin{array}{c}\text { Seismic } \\
\text { zones }\end{array}$ & $\begin{array}{c}\text { No. of } \\
\text { earthquakes }\end{array}$ & $\left(M_{\text {max }}\right)$ Obs. & $a$ & $b$ & $M_{\text {c }}$ \\
\hline 1 & Zone 1 & 2108 & 7.6 & 6.18 & 1.03 & $4.6( \pm 0.10)$ \\
2 & Zone 2 & 1062 & 7.0 & 5.14 & 0.90 & $4.7( \pm 0.09)$ \\
3 & Zone 3 & 745 & 7.7 & 5.08 & 0.91 & $4.6( \pm 0.09)$ \\
4 & Zone 4 & 411 & 8.0 & 4.41 & 0.80 & $4.6( \pm 0.11)$ \\
5 & Zone 5 & 194 & 6.6 & 4.28 & 0.86 & $4.6( \pm 0.16)$ \\
\hline
\end{tabular}

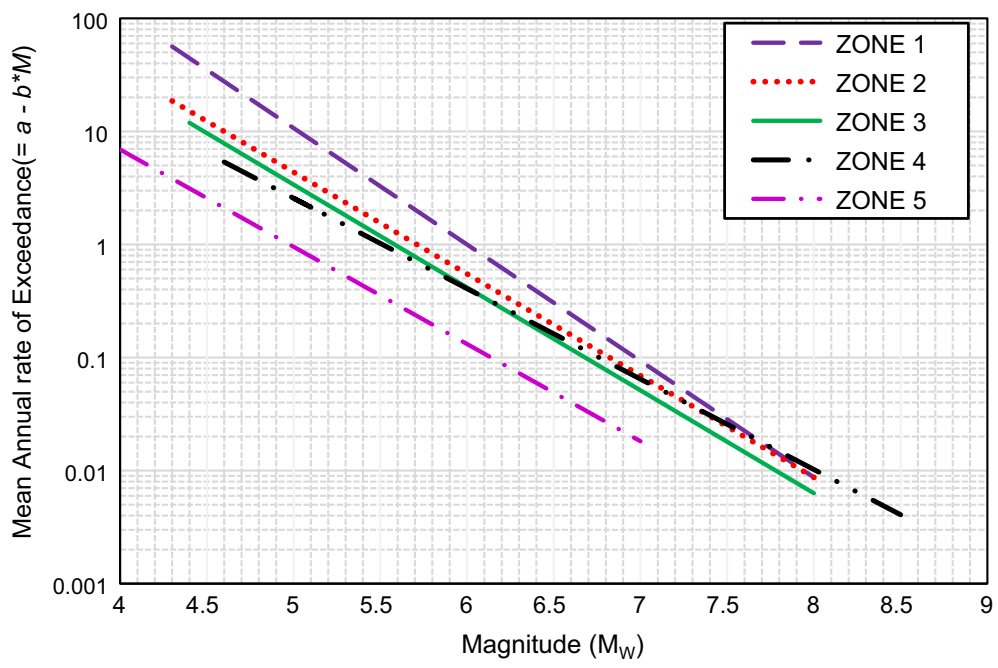

Figure 11. Mean annual rate of exceedance for each zone.

rate of exceedance of different magnitudes of each zone is plotted using $\mathrm{G}-\mathrm{R}$ recurrence law as given in equation (1) and shown in figure 11. Using the estimated values of $a$ and $b$, the return period and probability of occurrences of earthquakes of different magnitudes in 50 and 100 yr time period was also estimated for each zone. The return period and probability were calculated using equations (3) and (4), respectively, as given below:

$$
\begin{aligned}
\operatorname{Return} \text { period }\left(T_{R}\right) & =\frac{1}{m}, \\
\text { Probability }(P(M)) & =1-\mathrm{e}^{-\lambda_{m} T},
\end{aligned}
$$

where $\lambda_{m}$ is obtained using equation (1) and $T$ is the time period, which is considered as 50 and $100 \mathrm{yr}$ in this study, as the estimated lifetime for most of the engineering structures are generally 50 and $100 \mathrm{yr}$.

The return period and probability of future earthquakes in each zone for 50 and $100 \mathrm{yr}$ are shown in figures 12-14, respectively. For magnitudes 6,7 and 8, the estimated return period and probability in 50 and $100 \mathrm{yr}$ time period is given in table 3 . The return period of magnitude 6.0 in the study area varies from $1 \mathrm{yr}$ in zone 1 to 7.59 yr in zone 5. Similarly, for magnitude 7, the return period is the lowest for zone 1 (10.72 yr) and the highest for zone 5 (54.95 yr). For magnitude 8 , the return period is the lowest for zone 1 (114.82 yr) and the highest for zone 3 (158.49 yr) excluding zone 5 as it has never experienced any earthquake of magnitude 8 in the past. The zone 1 shows lowest return periods for all magnitudes, inferring it as the most seismically active zone in the entire study area. From the probability curve, it is observed that the probability of occurrences of earthquake decreases exponentially with magnitude. For all zones, a high probability of occurrence is observed for magnitude 6 earthquake both in 50 and $100 \mathrm{yr}$ of time period. Also, for magnitude 7, a high probability $(>0.9)$ is observed for 50 and $100 \mathrm{yr}$ of time period in all zones except zone 5 . For magnitude 8 more than $50 \%$ probability is observed in 100 yr time period for zone 1 and 2. For other zones, both in 50 and $100 \mathrm{yr}$ time period, the probability of occurrence of magnitude 8 earthquake is less than $50 \%$. This high value of probability in zones 1 to 4, predicts that the Himalayan region has a high probability of occurrence of moderate 


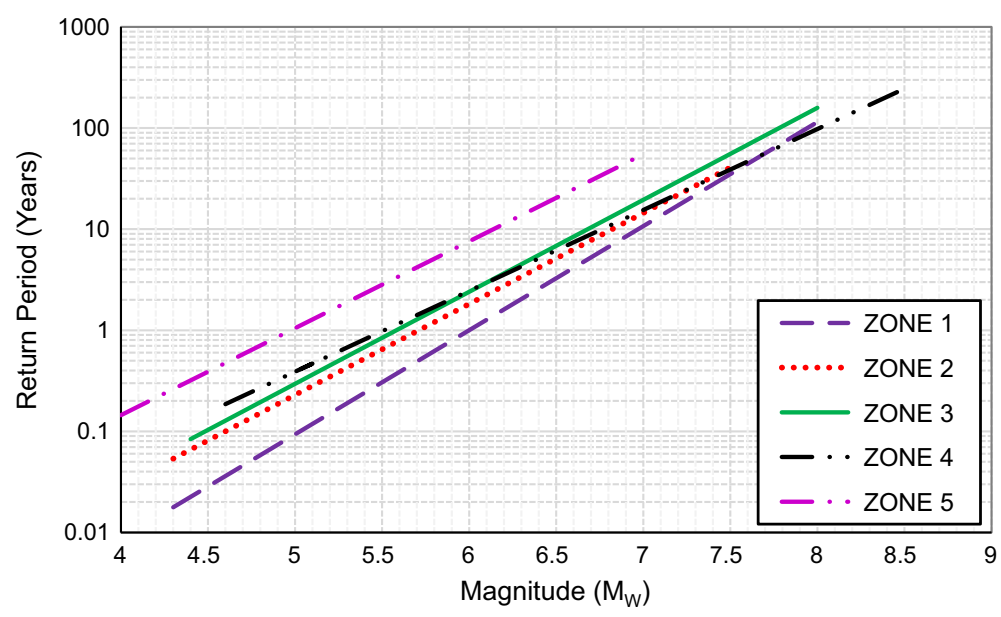

Figure 12. Return period of different magnitude for each zone.

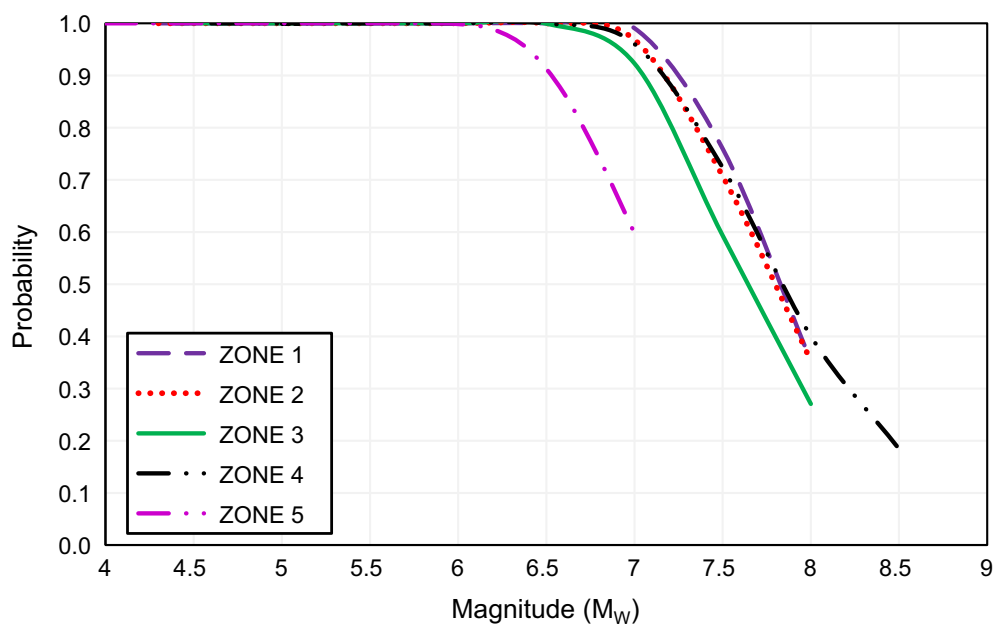

Figure 13. Probability of different magnitude for a time period of $50 \mathrm{yr}$ in each zone.

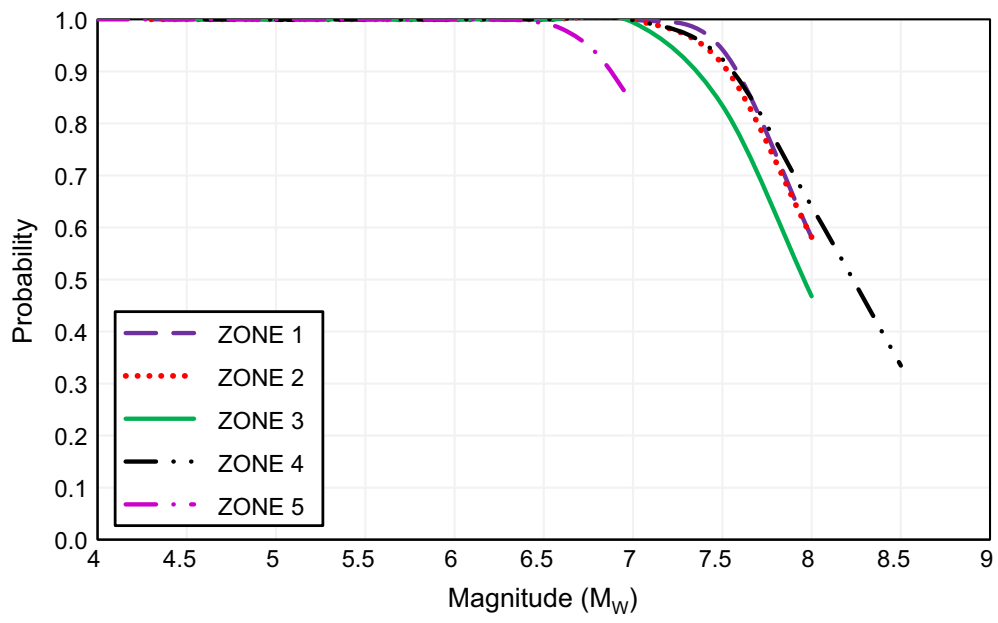

Figure 14. Probability of different magnitude for a time period of $100 \mathrm{yr}$ in each zone. 
Table 3. Estimated return period (in yr) and probability of occurrence in 50 and 100 yr for earthquakes with magnitude 6, 7 and 8 in all the five zones.

\begin{tabular}{|c|c|c|c|c|c|c|c|c|c|c|}
\hline \multirow{2}{*}{$\begin{array}{l}\text { Sl. } \\
\text { no. }\end{array}$} & \multirow{2}{*}{$\begin{array}{l}\text { Seismic } \\
\text { zone }\end{array}$} & \multicolumn{3}{|c|}{ Return period (yr) } & \multicolumn{3}{|c|}{ Probability in 50 yrs } & \multicolumn{3}{|c|}{ Probability in 100 yrs } \\
\hline & & $M=6.0$ & $M=7.0$ & $M=8.0$ & $M=6.0$ & $M=7.0$ & $M=8.0$ & $M=6.0$ & $M=7.0$ & $M=8.0$ \\
\hline 1 & Zone 1 & 1.00 & 10.72 & 114.82 & 1.00 & 0.99 & 0.35 & 1.00 & 1.00 & 0.58 \\
\hline 2 & Zone 2 & 1.82 & 14.45 & 114.82 & 1.00 & 0.97 & 0.35 & 1.00 & 1.00 & 0.58 \\
\hline 3 & Zone 3 & 2.40 & 19.50 & 158.49 & 1.00 & 0.92 & 0.27 & 1.00 & 0.99 & 0.47 \\
\hline 4 & Zone 4 & 2.45 & 15.49 & 145.47 & 1.00 & 0.96 & 0.18 & 1.00 & 1.00 & 0.33 \\
\hline 5 & Zone 5 & 7.59 & 54.95 & & 1.00 & 0.60 & & 1.00 & 0.84 & \\
\hline
\end{tabular}

to high earthquake. Similarly, zones $3-5$, which fall into the Indo-Gangetic plain region, have a probability of moderate to small earthquake in 50 to 100 yr of time period.

\section{Conclusions}

A homogeneous earthquake event catalogue based on moment magnitude scale was prepared using region-specific magnitude scaling relation for western Himalaya, central Himalaya and Indo-Gangetic plain of Indian subcontinent from the earliest period till 2016. The seismicity analysis suggested that most of the earthquakes have occurred in the Himalayan area specifically the western part. The maximum likelihood estimation of seismic parameter $b$ gave a value of 0.87 with standard deviation of 0.03 and seismic parameter $a$ as 8.13 for the entire study region, suggesting a typical value for seismically active region. The present analysis for seismicity parameters of western Himalaya, central Himalaya and Indo-Gangetic plain shows a reasonable good match to various researchers in previous studies. The seismicity parameter $b$ not only gives magnitude size distribution of a region but also gives an indication of the crustal stress level. A low $b$ value $(<1.0)$ shows high crustal stress and also material heterogeneity. As in most part of the study area, the value of $b$ is $<0.9$, it suggests that crustal stress level is high and goes on building up due to continuous movement of Indian plate towards Eurasian plate. This increases the probability of occurrence of future large earthquakes in this part of India. Based on variation of seismicity pattern throughout the study area, five seismic source zones were identified assuming similar level of seismicity within these zones. Finally, the corresponding seismicity parameters were evaluated for each seismic source zones. Based on seismicity parameters of each zone, the return period and probability of occurrence of future earthquakes in the time period of 50 and 100 yr was estimated. From these it is concluded that zone 1 is the most seismically active region which is in the northwest Himalayan region, whereas zone 5 is least active which is in the Indo-Gangetic plain region. Again, depending on probability values, it can be concluded that the northwest and central Himalayan region might expect moderate to large future earthquake whereas small to moderate earthquake might hit in the Indo-Gangetic plain region.

\section{References}

Aki K 1965 Maximum likelihood estimate of $b$ in the formula $\log N=a-b M$ and its confidence limits; Bull. Earthq. Res. Inst. Univ. Tokyo 43 237-239.

Ali S M and Shanker D 2017 Study of seismicity in the NW Himalaya and adjoining regions using IMS network; $J$. Seismol. 21(2) 317-334.

Avouac J P, Meng L, Wei S, Wang T and Ampuero J P 2015 Lower edge of locked main Himalayan thrust unzipped by the 2015 Gorkha earthquake; Nat. Geosci. 8(9) 708-711.

Bender B 1983 Maximum likelihood estimation of $b$ values for magnitude grouped data; Bull. Seismol. Soc. Am. 73(3) 831-851.

Bilham R, Gaur V K and Molnar P 2001 Himalayan seismic hazard; Science 293(5534) 1442-1444.

Bungum H, Lindholm C D and Mahajan A K 2017 Earthquake recurrence in NW and central Himalaya; J. Asian Earth Sci. 138 25-37.

Chernick M R 1999 Bootstrap methods: A practitioners guide; Wiley Series in Probability and Statistics, Wiley, New York.

Chingtham P, Chopra S, Baskoutas I and Bansal B K 2014 An assessment of seismicity parameters in northwest Himalaya and adjoining regions; J. Nat. Hazards 71(3) 1599-1616.

Chingtham P, Yadav R B S, Chopra S, Yadav A K, Gupta A K and Roy P N S 2016 Time-dependent seismicity analysis in the Northwest Himalaya and its adjoining regions; Nat. Hazards 80(3) 1783-1800.

Das R, Wason H R and Sharma M L 2013 General orthogonal regression relations between body-wave and moment magnitudes; Seismol. Res. Lett. 84(2) 219-224.

Gutenberg B and Richter C F 1944 Frequency of earthquakes in California; Bull. Seismol. Soc. Am. 34(4) 185-188. 
Kayal J R 2008 Microearthquake seismology and seismotectonics of South Asia; 1st edn, Springer and Capital Publishing Company, India, ISBN: 978-1-4020-8180-4.

Kolathayar S and Sitharam T G 2012 Characterization of regional seismic source zones in and around India; Seismol. Res. Lett. 83(1) 77-85.

Kolathayar S, Sitharam T G and Vipin K S 2012 Spatial variation of seismicity parameters across India and adjoining areas; Nat. Hazards 60(3) 1365-1379.

NDMA (National Disaster Management Authority) 2011 Development of probabilistic seismic hazard map of India 2011. Appendix I: Catalogue of earthquakes of moment magnitude $\geq 4.0$ in and around India assembled from eighteen sources; Government of India, New Delhi.

Raghukanth S T G 2010 Estimation of seismicity parameters for India; Seismol. Res. Lett. 81(2) 207-217.

Rajendran C P and Rajendran K 2005 The status of central seismic gap a perspective based on the spatial and temporal aspects of the large Himalayan earthquakes; Tectonophys. 395(1) 19-39.

Rout M M, Das J and Kamal 2013 Temporal and spatial variations of seismicity parameters for Northwest Himalaya; Geosci. Remote Sens. Symp. (IGARSS), 2013 IEEE Int., pp. 3690-3693.

Rydelek P A and Sacks I S 1989 Testing the completeness of earthquake catalogues and the hypothesis of self-similarity; Nature 337(6204) 251-253.

Schorlemmer D, Neri G, Wieme S and Mostaccio A 2003 Stability and significance tests for $b$-value anomalies: Example from the Tyrrhenian Sea; Geophys. Res. Lett. 30(16), https://doi.org/10.1029/2003GL017335.

SEISAT 2000 Seismotectonic atlas of India and its environs; Geological Survey of India, New Delhi.

Shanker D and Sharma M L 1998 Estimation of seismic hazard parameters for the Himalayas and its vicinity from complete data files; Pure Appl. Geophys. 152(2) 267-279.

Singh M and Shanker D 2015 Seismic hazard assessment in Hindukush-Pamir Himalaya using IMS network; $J$. Geosci. 5(3) 81-85.

Corresponding editor: Munukutla RADHAKRISHnA
Stepp J C 1972 Analysis of completeness of the earthquake sample in the Puget Sound area and its effect on statistical estimates of earthquake hazard; In: Proceedings of the International Conference on Microzonazion, Seattle, Washington, Vol. 2, pp. 897-910.

Stevens V L and Avouac J 2016 Millenary $\mathrm{M}_{\mathrm{w}}>9.0$ earthquake required by geodetic strain in the Himalaya; Geophys. Res. Lett. 43 1118-1123.

Uhrhammer R A 1986 Characteristics of northern and central California seismicity; Earthq. Notes 57(1) 21.

Utsu T 1965 A method for determining the value of $b$ in a formula $\log n=a-b M$ showing the magnitude-frequency relation for earthquakes; Geophys. Bull. Hokkaido Univ. 13 99-103.

Utsu T 1999 Representation and analysis of the earthquake size distribution: A historical review and some new approaches; Pure Appl. Geophys. 155(2-4) 509-535.

Wason H R, Das R and Sharma M L 2012 Magnitude conversion problem using general orthogonal regression; Geophys. J. Int. 190(2) 1091-1096.

Wiemer S 2001 A software package to analyze seismicity: ZMAP; Seismol. Res. Lett. 72(3) 373-382.

Wiemer S and Wyss M 2000 Minimum magnitude of completeness in earthquake catalogues: Examples from Alaska, the western United States, and Japan; Bull. Seismol. Soc. Am. 90(4) 859-869.

Woessner J and Wiemer S 2005 Assessing the quality of earthquake catalogues: Estimating the magnitude of completeness and its uncertainty; Bull. Seismol. Soc. Am. 95(2) 684-698.

Yadav R B S, Bayrak Y, Tripathi J N, Chopra S, Singh A P and Bayrak E 2012 A probabilistic assessment of earthquake hazard parameters in NW Himalaya and the adjoining regions; Pure Appl. Geophys. 169(9) 1619-1639.

Yadav R B S, Tsapanos T M, Bayrak Y, Koravos G C and Devlioti K D 2013 Spatial mapping of earthquake hazard parameters in the Hindukush-Pamir Himalaya and adjacent regions: Implication for future seismic hazard; J. Asian Earth Sci. 70 115-124. 